\title{
Pretherapeutic gamma-glutamyltransferase is an independent prognostic factor for patients with renal cell carcinoma
}

\author{
S L Hofbauer ${ }^{1,4}, \mathrm{~K}_{\text {I Stangl }}{ }^{1,4}, \mathrm{M}$ de Martino ${ }^{1}$, I Lucca $^{1,2}$, A Haitel $^{3}$, S F Shariat ${ }^{1}$ and T Klatte ${ }^{*, 1}$
}

${ }^{1}$ Department of Urology, Comprehensive Cancer Center, Medical University of Vienna and General Hospital, Währinger Gürtel 18-20, 1090 Vienna, Austria; ${ }^{2}$ Department of Urology, Centre hospitalier universitaire vaudois, Rue du Bugnon 46,1011 Lausanne, Switzerland and ${ }^{3}$ Clinical Institute of Pathology, Medical University of Vienna, Vienna General Hospital, Währinger Gürtel 18-20, 1090 Vienna, Austria

Background: Gamma-glutamyltransferase (GGT) regulates apoptotic balance and promotes cancer progression and invasion. Higher pretherapeutic GGT serum levels have been associated with worse outcomes in various malignancies, but there are no data for renal cell carcinoma (RCC).

Methods: Pretherapeutic GGT serum levels and clinicopathological parameters were retrospectively evaluated in 921 consecutive RCC patients treated with nephrectomy at a single institution between 1998 and 2013. Gamma-glutamyltransferase was analysed as continuous and categorical variable. Associations with RCC-specific survival were assessed with Cox proportional hazards models. Discrimination was measured with the C-index. Decision-curve analysis was used to evaluate the clinical net benefit. The median postoperative follow-up was 45 months.

Results: Median pretherapeutic serum GGT level was $25 \mathrm{UI}^{-1}$. Gamma-glutamyltransferase levels increased with advancing T $(P<0.001), N(P=0.006)$ and $M$ stages $(P<0.001)$, higher grades $(P<0.001)$, and presence of tumour necrosis $(P<0.001)$. An increase of GGT by $10 \mathrm{UI}^{-1}$ was associated with an increase in the risk of death from RCC by $4 \%(H R 1.04, P<0.001)$. Based on recursive partitioning-based survival tree analysis, we defined four prognostic categories of GGT: normal low $\left(<17.5 \mathrm{UI}{ }^{-1}\right)$, normal high $\left(17.5\right.$ to $\left.<34.5 \mathrm{UI}^{-1}\right)$, elevated $\left(34.5\right.$ to $\left.<181.5 \mathrm{UI}^{-1}\right)$, and highly elevated $\left(\geqslant 181.5 \mathrm{UI}^{-1}\right)$. In multivariable analyses that adjusted for the effect of standard features, both continuously and categorically coded GGT were independent prognostic factors. Adding GGT to a model that included standard features increased the discrimination by $0.9 \%$ to $1.8 \%$ and improved the clinical net benefit.

Conclusions: Pretherapeutic serum GGT is a novel and independent prognostic factor for patients with RCC. Stratifying patients into prognostic subgroups according to GGT may be used for patient counselling, tailoring surveillance, individualised treatment planning, and clinical trial design.

Renal cell carcinoma (RCC) accounts for $>90 \%$ of kidney cancers and for $2-3 \%$ of all adult malignancies (Jemal et al, 2011). In the European Union, there were $~ 88400$ new cases and over 39000 deaths from RCC in 2008 (Ljungberg et al, 2010). Approximately, $20 \%$ of patients present with metastatic disease and another $20 \%$ will develop metastases after being considered disease-free (de
Martino et al, 2013; Pichler et al, 2013). Once metastatic, patients with RCC have a poor prognosis with a median survival time of $\sim 2$ years (Procopio et al, 2012). Prognostic factors that identify patients at an increased risk of recurrence, progression, and RCC-related death are needed to allow patient stratification into groups, which would facilitate clinical decision-making regarding

\footnotetext{
*Correspondence: Dr T Klatte; E-mail: tobias.klatte@gmx.de
}

${ }^{4}$ These authors contributed equally to this work.

Received 7 May 2014; revised 13 July 2014; accepted 15 July 2014; published online 12 August 2014 
surveillance scheduling, treatment planning in metastatic disease, and clinical trial design.

Besides its clinical use as a routine marker for hepatobiliary disease, studies indicate that the gamma-glutamyltransferase (GGT) plays an important role in cancer development and cancer progression (Whitfield, 2001; Corti et al, 2010). Gamma-glutamyltransferase is a membrane bound enzyme that is involved in the glutathione (GSH) metabolism. Glutathione is the main watersoluble antioxidant within the cell, neutralising reactive oxygen compounds and free radicals (Pastore et al, 2003). Both GGT and GSH are regularly elevated in pathological states of oxidative stress (Whitfield, 2001). In addition, GSH has been linked to tumour growth and survival, as it is the major provider of cysteine for the cell. Adequate supply with cysteine is essential for protein synthesis, especially for fast-dividing neoplastic cells (Hanigan and Ricketts, 1993). Recently, GGT has gained some attention as a prognostic biomarker for several types of cancer (Seebacher et al, 2012; Grimm et al, 2013), but there are no reports in RCC to our knowledge. We hypothesised that GGT plays an important role in RCC progression and metastasis. To test this, pretherapeutic GGT levels were associated with survival in a large consecutive cohort of patients with RCC.

\section{PATIENTS AND METHODS}

Institutional review board. The present study was approved by the institutional review board of the Medical University of Vienna and the Vienna General Hospital (protocol registration number 1201/2014) and performed according to the REMARK guidelines (McShane et al, 2005).

Patients. A total of 1287 patients with unilateral sporadic renal tumours were screened for inclusion in this single centre retrospective study. All patients underwent radical or partial nephrectomy for suspected RCC at the Department of Urology, Comprehensive Cancer Centre, Medical University of Vienna, Vienna, Austria, between 1998 and 2013.

Patients who were found to have renal tumours other than RCC $(n=219)$ and those with pre-existing comorbidities or medications related to elevated GGT (i.e., concomitant malignant disease, acute or chronic pancreatitis, acute or chronic hepatitis, liver cirrhosis, intra- or post-hepatic biliary obstruction, cholangitis, congestive heart failure NYHA III-IV, thyreostatic drugs, anticonvulsants, and alcohol abuse, $n=147$ ) were excluded from the study. The final cohort comprised 921 patients. Clinical, laboratory, pathological, treatment, and follow-up data of these patients were extracted from electronic oncology registries.

Therapeutic management. Before surgery, a physical examination by a consultant in internal medicine and blood tests were conducted. All patients had a CT scan of the abdomen and an X-ray or a CT scan of the chest. If symptoms or abnormal laboratory signs exist, further imaging of the bones and brain was performed.

None of the patients had preoperative systemic therapy, local radiotherapy or embolisation. A total of 577 patients (63\%) underwent radical nephrectomy, while 344 (37\%) had partial nephrectomy. Patients with suspicious nodes on imaging or during the operation underwent a concomitant regional lymph node dissection $(n=155)$, with a median of four lymph nodes removed (range 1-25). Every other case was $\mathrm{pNx}$ but judged clinical N0. No patient received adjuvant therapy. Patients were further treated and generally followed according to the guidelines released by the European Association of Urology at that time. If patients did not present for scheduled follow-up visits, they were contacted by administrative personnel or through the primary care physician. The median follow-up interval was 45 months (interquartile range,
IQR 19-82). There were 103 deaths from RCC. All patients that died from RCC had widespread metastatic disease.

Diagnosis of RCC and subtype were established by histological examination of the surgical specimen according to the World Health Organization classification. The final T, N, or M stage was reassigned according to the 2009 Tumour, Node, Metastasis classification of the Union internationale contre le cancer. T stage was assigned pathologically and $\mathrm{M}$ stage was assigned clinically. Nuclear grade was assigned according to Fuhrman criteria. Presence of histological tumour necrosis was recorded prospectively. Over the entire study period, all histological examinations were performed by three expert uropathologists. Histological slides from 1998 to 2009 were re-reviewed by one pathologist (AH) for grade and subtype.

Gamma-glutamyltransferase measurement. Blood samples were obtained routinely by peripheral venous puncture within 3 days prior to surgery. All analyses were performed in the central laboratory of the Medical University of Vienna, which undergoes regular internal and external quality controls (accreditation number 0267, EN ISO 15189). Serum GGT levels were measured at $37^{\circ} \mathrm{C}$ on the day of sample collection. Measurements were performed with a Roche/Hitachi analyser (Modular Hitachi 747, Vienna, Austria) until 2008 and with an Olympus 5400 analyser (Vienna, Austria) thereafter using enzymatic colorimetric assays (Roche Diagnostics, Vienna, Austria). Gamma-glutamyltransferase activity was determined at $405 \mathrm{~nm}$ using $\gamma$-L-glutamyl-4-nitroanilide as the substrate and glycylglycine as an acceptor, which form 4-nitroanailine. All samples were assayed in duplicate. The intraassay coefficient of variation was $2.3 \%$. The normal values for the enzymatic colorimetric assay were $8-54 \mathrm{Ul}^{-1}$ for men and $6-38 \mathrm{Ul}^{-1}$ for women.

Statistical analysis. Gamma-glutamyltransferase levels were primarily analysed as continuous variable and are presented as medians and IQR. According to histogram plotting and ShapiroWilk statistics, GGT levels were not normally distributed. The Kruskal-Wallis test was therefore used to assess associations between GGT and categorical clinicopathological variables. Correlations were assessed with Spearman's rank correlation.

The primary point of interest was RCC-specific survival, which was calculated from the date of surgery to the date of death from RCC or last follow-up. Cause of death was determined from the death certificate or the clinical history. Patients who died from other causes or patients alive were censored with the date of death or last follow-up, respectively. The date of death and the cause of death were verified by the Austrian death registry.

Survival probabilities were calculated by the product limit Kaplan-Meier method, and differences were evaluated with logrank tests. Univariable and multivariable Cox regression models were fitted. Multivariable models adjusted for the effect of standard prognostic factors including $\mathrm{T}$ stage (T3-4 vs $\mathrm{T} 1-2), \mathrm{N}$ stage $(\mathrm{N}+$ vs N0), M stage (M1 vs M0), Fuhrman grade (G3-4 vs G1-2), necrosis (present $v s$ absent), and histologic subtype (clear cell $v s$ non-clear cell). In addition to a model with continuously coded GGT, a model with categorically coded GGT was fitted. Cutpoints for stratification were obtained from the nodes in recursive partitioning survival tree analysis. Results of Cox models are presented as hazard ratio (HR), 95\% confidence interval (95\% CI), and $P$-value. Owing to the fairly low numbers of events, there was a significant risk of overfit in multivariable modelling. Therefore, in a second set of multivariable analyses, we summarised prognostic factors with the SSIGN score (Frank et al, 2002) and the University of California Integrated Staging System (UISS; Zisman et al, 2002). Multivariable models were internally validated by bootstrapping (200 re-samples). Schoenfeld's global test was applied to test the proportional hazards assumption. Discrimination of Cox models was assessed with Harrell's concordance index. Discriminations 
between nested models were compared with likelihood ratio tests. Decision-curve analysis was performed to determine whether models with GGT increased the net benefit over a realistic range of threshold probabilities compared with the base model. All statistical testing was two-sided. $P$-values $<0.05$ were considered statistically significant. The statistical package STATA was used for all analyses.

\section{RESULTS}

Clinical and pathological characteristics. Patient characteristics are shown in Table 1 . Median age at the time of surgery was 64 years (IQR, 55-72). One hundred and thirty patients (14.1\%) presented with lymph node or distant metastases. Further treatment of these patients following cytoreductive nephrectomy consisted of immunotherapy $(33.1 \%)$, TKI (36.2\%), metastasectomy (3.8\%) or supportive care $(26.9 \%)$. The majority of tumours were clear cell $(74.4 \%)$.

Association of preoperative serum GGT with clinicopathological parameters. Median pretherapeutic GGT was $25 \mathrm{Ul}^{-1}$ (IQR, 15$\left.55 \mathrm{Ul}^{-1}\right)$. Gamma-glutamyltransferase increased with advancing $\mathrm{T}$ stage $(P<0.001)$ and Fuhrman grade $(P<0.001)$, and was higher in patients with lymph node metastases $(P=0.006)$, distant metastases $(P<0.001)$, and tumours with histological tumour necrosis $(P<0.001)$. Additionally, men had significantly higher GGT levels than women $(P<0.001)$. In multivariable linear regression analysis,

\begin{tabular}{|c|c|c|c|}
\hline Variable & $N(\%)$ & Median (IQR; $\mathrm{UI}^{-1}$ ) & $P$ \\
\hline Gender & & & $<0.001$ \\
\hline $\begin{array}{l}\text { Female } \\
\text { Male }\end{array}$ & $\begin{array}{l}332(36.0) \\
589(63.9)\end{array}$ & $\begin{array}{l}20(12-38) \\
28(18-48)\end{array}$ & \\
\hline pT stage & & & $<0.001$ \\
\hline $\begin{array}{l}\text { PT1-2 } \\
\text { pT3-4 }\end{array}$ & $\begin{array}{l}548(59.5) \\
373(40.5)\end{array}$ & $\begin{array}{l}23(14-38) \\
30(18-52)\end{array}$ & \\
\hline $\mathrm{pN}$ stage & & & 0.006 \\
\hline $\begin{array}{l}\mathrm{pNx} / \mathrm{NO} \\
\mathrm{pN}+\end{array}$ & $\begin{array}{l}892(96.9) \\
29(3.1)\end{array}$ & $\begin{array}{l}24(15-43) \\
47(21-92)\end{array}$ & \\
\hline M stage & & & $<0.001$ \\
\hline $\begin{array}{l}\text { M0 } \\
\text { M1 }\end{array}$ & $\begin{array}{l}803(87.2) \\
118(12.8)\end{array}$ & $\begin{array}{l}23(14-40) \\
41(25-74)\end{array}$ & \\
\hline Fuhrman grade & & & $<0.001$ \\
\hline $\begin{array}{l}\text { G1-2 } \\
\text { G3-4 }\end{array}$ & $\begin{array}{l}685(74.4) \\
236(25.6)\end{array}$ & $\begin{array}{l}23(14-40) \\
30(19-55)\end{array}$ & \\
\hline Tumour necrosis & & & $<0.001$ \\
\hline $\begin{array}{l}\text { Absent } \\
\text { Present }\end{array}$ & $\begin{array}{l}583(63.3) \\
338(36.7)\end{array}$ & $\begin{array}{l}22(14-40) \\
29(18-49)\end{array}$ & \\
\hline Subtype & & & 0.14 \\
\hline $\begin{array}{l}\text { Clear cell } \\
\text { Papillary } \\
\text { Chromophobe }\end{array}$ & $\begin{array}{l}685(74.4) \\
160(17.4) \\
76(8.3)\end{array}$ & $\begin{array}{l}26(15-46) \\
24(15-38) \\
22(13-40)\end{array}$ & \\
\hline Surgical approach & & & 0.74 \\
\hline $\begin{array}{l}\text { Radical nephrectomy } \\
\text { Partial nephrectomy }\end{array}$ & $\begin{array}{l}577(62.6) \\
344(37.4) \\
\end{array}$ & $\begin{array}{l}24(15-46) \\
26(16-41) \\
\end{array}$ & \\
\hline \multicolumn{4}{|c|}{$\begin{array}{l}\text { Abbreviations: } G G T=\text { gamma-glutamyltransferase; } G 1-4=\text { Fuhrman grade } 1-4 ; \quad I Q R= \\
\text { interquartile range; } M=\text { metastasis; } M 0=n o \text { distant metastasis; } M 1=\text { distant metastasis; } \\
\mathrm{pN}=\text { pathologic lymph node stage; } \mathrm{pN} / \mathrm{N} 0=\text { lymph nodes not evaluated/tumour cells } \\
\text { absent from regional lymph nodes; } \mathrm{pN}+=\text { presence of lymph node metastasis; } \\
\mathrm{pT}=\text { pathologic tumour stage; } \mathrm{pT} 1-4=\text { size and/or extension of primary tumour. }\end{array}$} \\
\hline
\end{tabular}

gender lost its significant association with GGT $(P=0.22)$. There was no association with histologic subtype $(P=0.14)$ and type of surgical treatment $(P=0.74)$, and GGT did not correlate with age $(R=-0.02, \quad P=0.38)$, pathological tumour size $(R=0.003$, $P=0.93)$, body mass index $(R=-0.01, P=0.82)$, bilirubin levels $(R=0.004, P=0.89)$, and alkaline phosphatase levels $(R=0.028$, $P=0.42)$. There was a statistically significant correlation with AST $(R=0.43, P<0.001)$ and ALT $(R=0.23, P<0.001)$.

Association of preoperative serum GGT with survival. In univariable analysis, each $10 \mathrm{Ul}^{-1}$ increase in GGT was associated with a $4 \%$ increase in the risk of death from RCC (HR 1.04, 95\% CI $1.03-1.05, P<0.001)$. For substratification, the following four groups were defined based on the partitioning nodes: normal low $\left(<17.5 \mathrm{Ul}^{-1}\right)$, normal high $\left(17.5\right.$ to $\left.<34.5 \mathrm{Ul}^{-1}\right)$, elevated $(34.5$ to $\left.<181.5 \mathrm{Ul}^{-1}\right)$, and highly elevated $\left(\geqslant 181.5 \mathrm{Ul}^{-1}\right)$. Of the 921 patients, 289 (31.4\%) had normal low GGT, 315 (34.2\%) had normal high GGT, 296 (32.1\%) had elevated, and 21 (2.3\%) highly elevated GGT. These groups differed significantly in terms of RCCspecific survival (Figure 1). Five-year survival probabilities are presented in Table 2.

In multivariable analysis that adjusted for the effect of standard prognostic factors, every $10 \mathrm{Ul}^{-1}$ increase in GGT was associated with a $3 \%$ increased risk of death from RCC $(P=0.001$, Table $3 \mathrm{~A})$.

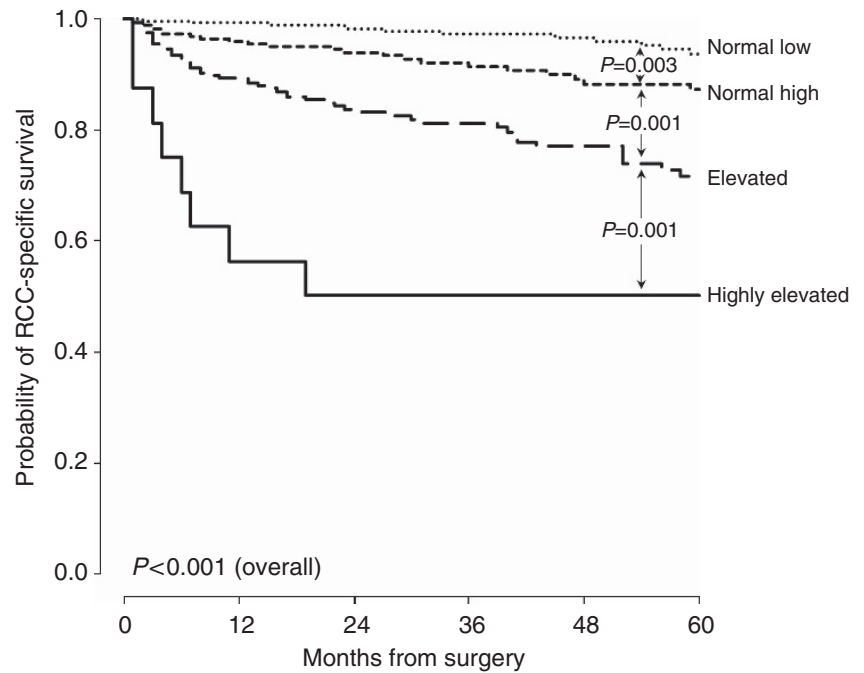

No. at risk

$\begin{array}{lrrrrr}\text { Normal low } & 231 & 194 & 170 & 154 & 120 \\ \text { Normal high } & 214 & 164 & 132 & 107 & 84 \\ \text { Elevated } & 193 & 141 & 108 & 82 & 55 \\ \text { Highly elevated } & 9 & 5 & 3 & 3 & 1\end{array}$

Figure 1. Kaplan-Meier survival estimates of RCC-specific survival for 921 patients treated with nephrectomy for RCC according to GGT groups.

Table 2. Categorically coded GGT levels and 5-year RCC-specific survival rates

\begin{tabular}{|l|l|c|c|}
\hline Group & Reference interval & $\mathbf{N}(\%)$ & $\begin{array}{c}\text { Percentage } \\
\text { at 5 years (s.e.) }\end{array}$ \\
\hline Normal low & $<17.5 \mathrm{UI}^{-1}$ & $289(31.4)$ & $93.7(1.9)$ \\
\hline Normal high & 17.5 to $<34.5 \mathrm{UI}^{-1}$ & $315(34.2)$ & $87.2(2.7)$ \\
\hline Elevated & 34.5 to $<181.5 \mathrm{UI}^{-1}$ & $296(32.1)$ & $71.6(3.8)$ \\
\hline Highly elevated & $\geqslant 181.5 \mathrm{UI}^{-1}$ & $21(2.3)$ & $50.0(12.5)$ \\
\hline \multicolumn{4}{|l|}{ Abbreviations: GGT = gamma-glutamyltransferase; RCC = renal cell carcinoma. } \\
\hline
\end{tabular}


Table 3. Multivariable Cox regression models for predicting RCC-specific survival of 921 patients treated with surgery for RCC, including (A) models with single pathological variables and summarised as SSIGN score (B) and UISS (C)

\begin{tabular}{|c|c|c|c|c|c|c|c|c|c|c|}
\hline & & \multicolumn{3}{|c|}{ Base model } & \multicolumn{3}{|c|}{ Continuous GGT } & \multicolumn{3}{|c|}{ Categorical GGT } \\
\hline & Categories & HR & $95 \% \mathrm{Cl}$ & $P$ & HR & $95 \% \mathrm{Cl}$ & $P$ & HR & $95 \% \mathrm{Cl}$ & $P$ \\
\hline \multicolumn{11}{|l|}{ A } \\
\hline T stage & pT3-4 vs pT1-2 & 2.52 & $1.48-4.28$ & 0.001 & 2.42 & $1.42-4.11$ & 0.001 & 2.48 & $1.46-4.19$ & 0.001 \\
\hline $\mathrm{N}$ stage & $\mathrm{pN}+v s \mathrm{pNx} / \mathrm{NO}$ & 2.22 & $1.27-3.89$ & 0.005 & 2.01 & $1.14-3.54$ & 0.015 & 1.96 & $1.08-3.56$ & 0.026 \\
\hline M stage & M1 vs M0 & 15.59 & $9.64-25.23$ & $<0.001$ & 15.23 & $9.38-24.72$ & $<0.001$ & 13.80 & $8.42-22.60$ & $<0.001$ \\
\hline Grade & G3-4 vs G1-2 & 1.91 & $1.24-2.95$ & 0.003 & 1.96 & $1.27-3.02$ & 0.002 & 1.83 & $1.19-2.82$ & 0.006 \\
\hline Necrosis & Present vs absent & 1.06 & $0.69-1.65$ & 0.78 & 1.11 & $0.71-1.73$ & 0.65 & 1.06 & $0.68-1.65$ & 0.81 \\
\hline Subtype & Clear vs not & 0.99 & $0.57-1.73$ & 0.98 & 0.93 & $0.54-1.63$ & 0.81 & 0.88 & $0.50-1.56$ & 0.67 \\
\hline GGT continuous & Continuous $^{\mathrm{a}}$ & - & - & - & 1.03 & $1.01-1.05$ & 0.001 & - & - & - \\
\hline \multirow[t]{4}{*}{ GGT categorical } & Normal low & - & - & - & - & - & - & 1.00 & & \\
\hline & Normal high & - & - & - & - & - & - & 1.82 & $0.96-3.47$ & 0.068 \\
\hline & Elevated & - & - & - & - & - & - & 3.05 & $1.66-5.62$ & $<0.001$ \\
\hline & Highly elevated & - & - & - & - & - & - & 5.60 & $2.17-14.46$ & $<0.001$ \\
\hline Discrimination, \% & & 88.7 & & & 89.6 & & & 90.5 & & \\
\hline \multicolumn{11}{|l|}{ B } \\
\hline SSIGN score & Continuous & 1.48 & $1.40-1.55$ & $<0.001$ & 1.45 & $1.38-1.53$ & $<0.001$ & 1.42 & $1.35-1.50$ & $<0.001$ \\
\hline GGT continuous & Continuous $^{a}$ & - & - & - & 1.04 & $1.02-1.06$ & $<0.001$ & - & - & - \\
\hline \multirow[t]{4}{*}{ GGT categorical } & Normal low & - & - & - & - & - & - & 1.00 & & \\
\hline & Normal high & - & - & - & - & - & - & 1.98 & $1.04-3.75$ & 0.036 \\
\hline & Elevated & - & - & - & - & - & - & 3.37 & $1.83-6.21$ & $<0.001$ \\
\hline & Highly elevated & - & - & - & - & - & - & 5.98 & $2.32-15.38$ & $<0.001$ \\
\hline Discrimination, \% & & 88.5 & & & 89.4 & & & 90.2 & & \\
\hline \multicolumn{11}{|l|}{ C } \\
\hline UISS & Continuous & 3.94 & $3.30-4.69$ & $<0.001$ & 3.85 & $3.23-4.59$ & $<0.001$ & 3.56 & $2.97-4.26$ & $<0.001$ \\
\hline GGT continuous & Continuous $^{a}$ & - & - & - & 1.02 & $1.01-1.04$ & 0.002 & - & - & - \\
\hline \multirow[t]{4}{*}{ GGT categorical } & Normal low & - & - & - & - & - & - & 1.00 & & \\
\hline & Normal high & - & - & - & - & - & - & 2.02 & $1.05-3.89$ & 0.035 \\
\hline & Elevated & - & - & - & - & - & - & 3.49 & $1.86-6.53$ & $<0.001$ \\
\hline & Highly elevated & - & - & - & - & - & - & 5.95 & $2.32-15.24$ & $<0.001$ \\
\hline Discrimination, \% & & 88.2 & & & 89.7 & & & 89.9 & & \\
\hline $\begin{array}{l}\text { Abbreviations: } \mathrm{Cl}=\mathrm{c} \\
\mathrm{GGT}=\text { gamma-glutam } \\
\text { regional lymph nodes } \\
\text { and Necrosis; } \mathrm{UISS}=\mathrm{L} \\
\mathrm{a}_{\mathrm{Per}} 10 \mathrm{UI}^{-1} \text {. }\end{array}$ & $\begin{array}{l}\text { e interval; G1-4 } \\
\text { rase; } \mathrm{HR}=\text { hazard } \\
\text { presence of lympl } \\
\text { of California Inte }\end{array}$ & tagi & $\begin{array}{l}\text { pT1-4 = } \\
\text { em. }\end{array}$ & ten & rim & $\begin{array}{l}\text { etastasis; } ; \text { pl } \\
\text { unr; } R C C=r\end{array}$ & $\begin{aligned} & \text { coded } \\
&= \text { lymph } n \\
& \text { ell carcino }\end{aligned}$ & $\begin{array}{l}\text { wer } \\
\text { not e } \\
\text { SSIGN }\end{array}$ & $\begin{array}{l}\text { gnificant progr } \\
\text { ted/tumour cel } \\
\text { ayo Clinic Stage }\end{array}$ & $\begin{array}{l}\text { tic factors } \\
\text { absent from } \\
\text { jize, Grade }\end{array}$ \\
\hline
\end{tabular}

In the multivariable model with categorically coded GGT, there was a continuous increase in the risk of death from RCC with increasing GGT categories (Table 3A). The base model with the variables T, N, $\mathrm{M}$ stages and nuclear grade, histologic subtype, and tumour necrosis achieved a discrimination of $88.7 \%$. Inclusion of continuously and categorically coded GGT increased the discrimination by $0.9 \%$ $(P=0.008)$ and by $1.8 \%(P<0.001)$, respectively.

In another set of multivariable analyses, prognostic variables were summarised as SSIGN score and UISS. Both continuously and categorically coded GGT were significant prognosticators (Table 3B and C). The discrimination of the SSIGN score increased after addition of continuously or categorically coded GGT to the model (from $88.5 \%$ to $89.4 \%, P=0.003$, and from $88.5 \%$ to $90.2 \%$, $P<0.001)$. Likewise, there was a significant increase in discrimination of UISS with continuously (from $88.2 \%$ to $89.7 \%, P<0.001$ ) and categorically coded GGT (from $88.2 \%$ to $89.9 \%, P<0.001$ ).

Decision-curve analysis was performed to determine whether models with GGT increased the net benefit over the base model. In this analysis, a small net benefit was noted for categorically coded GGT, while there was no difference in the curves between the base model and the model with continuously coded GGT (Figure 2).

\section{DISCUSSION}

This study shows that pretherapeutic serum GGT is an independent prognostic factor for patients with RCC, with higher levels being 


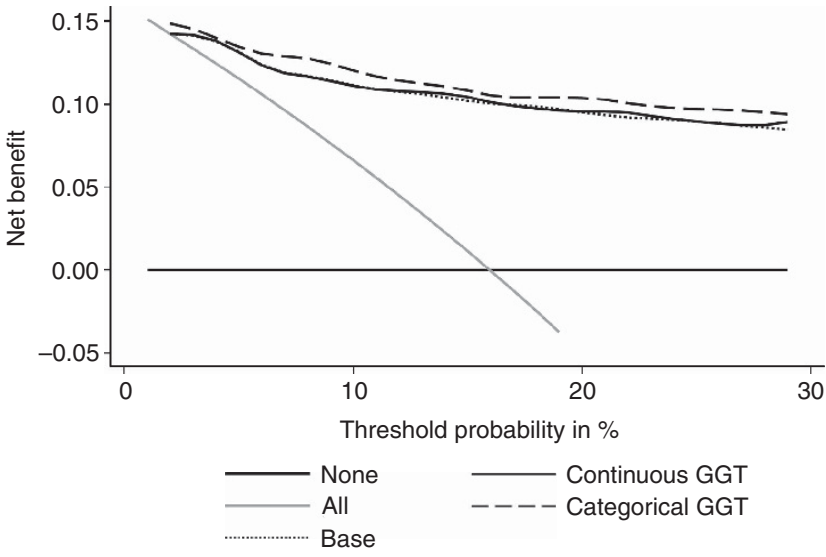

Figure 2. Decision-curve analysis for predicting RCC-specific survival. Categorically coded GGT conveyed a small increase in net benefit, while there was no difference in net benefit between the base model and the model with continuously coded GGT.

associated with worse outcomes. In addition to statistical significance in multivariable analysis, GGT increased the discrimination of a multivariable base model and improved the clinical net benefit.

Studies indicate that GGT is a prognostic biomarker for several cancer entities (Polterauer et al, 2011; Seebacher et al, 2012; Grimm et al, 2013), but data for RCC are limited. Previous studies focused on GGT levels in relation to metastatic disease, but did not evaluate survival. Sandock et al (1997) and Simic et al (2007) showed that GGT is elevated in patients with metastatic disease. In their studies comprising 82 and 216 patients, respectively, elevated levels of GGT were independently associated with metastatic disease irrespective of hepatic involvement. The authors hypothesised that GGT is increased due to quantitative changes in GGT expression and necrotic alterations within the tumour. These data are in line with the current study, which show higher levels of GGT in patients with advanced tumours and metastases. Ramankulov et al (2007) were not able to associate GGT with metastatic disease, but their study comprised only 80 patients. To our knowledge, the current study is the first to include a survival analysis. We show that higher serum GGT levels are associated with worse RCCspecific survival in both univariable and multivariable analyses. Importantly, categorically coded GGT increased the discrimination of a multivariable base model by a modest degree and led to an improvement in the decision-curve analysis.

In the present study, males had significantly higher GGT levels (median difference $8 \mathrm{Ul}^{-1}$ ) compared to their female counterparts $(P<0.001)$. It is known that serum levels of GGT differ between healthy men and women (Schiele et al, 1977), which is reflected in a higher upper reference interval for men. For healthy individuals in the $60+$ age group, gender differences in GGT are between 6.5 and $17.6 \mathrm{Ul}^{-1}$ for healthy individuals. In our RCC cohort, gender was not a predictor of GGT in the multivariable linear regression model $(P=0.22)$. Further, although GGT levels commonly increase with age and BMI (Lee et al, 2007), we found no association between these two variables and GGT. The variability of GGT in cancer cells may therefore be linked with an altered cancerous metabolism or the pivotal role of GGT in carcinogenesis and tumour progression. In addition, dietary and environmental factors may impact GGT in the serum and within the tumour, but were not assessed in the current study. Further prospective translational and basic research studies should focus on these issues.

For accurate prediction of RCC prognosis, one variable alone is not sufficient. Therefore, models have been established that combine several independent prognostic factors. As an example, the SSIGN score combines T, N, M stages, tumour size, grade, and necrosis to stratify patients into different risk groups (Frank et al,
2002). The discrimination of the SSIGN score is $>85 \%$, but it can be further improved with prognostic biomarkers (Ficarra et al, 2006; de Martino et al, 2012a,b). In the present study, the SSIGN score and the UISS were used as multivariable base model. Addition of GGT to the SSIGN score and the UISS revealed statistical significance and increased its discrimination by a modest margin. Importantly, addition of categorical GGT led to an improvement in the net benefit, as an increase in discrimination does not necessarily equal an improvement in clinical decisionmaking. As the SSIGN score was developed for clear cell RCC, the UISS was used for similar multivariable analyses (Zisman et al, 2002). Here, the discrimination and the increase in discrimination were comparable. Therefore, both scores appear to be applicable for prognostic stratification of the current RCC cohort.

In the past years, studies focused on the biology of GGT in cancer development, progression, and drug resistance. It has been shown that GGT and subsequently GSH are essential components of the antioxidant defence by quenching free radicals on DNA (Whitfield, 2001; Pastore et al, 2003). Through this mechanism, it is also able to protect cells from cytotoxic damage caused by various chemotherapeutic drugs (Russo et al, 1986). Further research revealed a role in assuring the proliferative-apoptotic balance by exerting pro-oxidant effects at the membrane surface level and in the extracellular microenvironment (Corti et al, 2010). By providing cysteine, GSH has been linked with tumour growth and survival (Hanigan and Ricketts, 1993).

In normal tissue, GGT activity has been shown on the luminal surface of secretory and absorptive cells including superficial cells of the bile ducts, bile capillaries, and the brush border membrane of the proximal tubules of normal kidneys (Fischer et al, 1991; Hanigan and Frierson, 1996). These surfaces are usually not connected to the circulation. In contrast, GGT is expressed over the entire cell surface in RCC (Fischer and Scherberich, 1996; Kaufmann et al, 1997) and is therefore accessible through the circulation. This may subsequently lead to elevated serum levels of GGT and higher intracellular levels of GSH (Lusini et al, 2001), which correlate with the tumour burden. In fact, GGT levels were significantly associated with tumour stage, grade, necrosis, and metastasis, although GGT levels may not be entirely explained by tumour burden. Further immunohistochemical studies may provide more information on the relationship between GGT expression within the tumour and serum levels in RCC patients.

Inadequate validation of potentially strong markers is a major problem in current biomarker research. As GGT is well established in clinical practice, subsequent evaluation of its clinical net benefit as a prognostic marker in patients with RCC in a large independent prospective cohort needs to be conducted. Thereafter, introduction of GGT as a clinical routine prognostic marker may be considered.

Several additional limitations of our study merit to be mentioned. Owing to the retrospective study design and the long study period, postoperative imaging and therapy were not standardised. The therapeutic management for metastatic RCC has changed within the study period. Compared to immunotherapy, new targeted therapies have shown superiority in terms of response and survival (Heng et al, 2013; Kroeger et al, 2013), which may have impacted our results. Further, the sample size and the relatively low number of events did not allow any further subanalyses. Cutpoint values for categorically coded GGT were ideal for our cohort of RCC patients, but differed slightly from those used for other malignancies (Strasak et al, 2010; Seebacher et al, 2012). By accepting cutpoints from other cancers that may not be perfectly applicable to RCC, the true prognostic value of GGT may be blurred (Mazumdar and Glassman, 2000). Hence, we have obtained cutpoints for RCC from the nodes of recursive partitioning and additionally evaluated GGT as continuously coded variable without categorisation. 
In summary, we identified pretherapeutic serum GGT as a novel and independent prognostic biomarker for patients with RCC. Gamma-glutamyltransferase improves the discrimination of established prognostic factors. Stratifying patients into subgroups according to GGT may be used for patient counselling, tailoring surveillance, individualised treatment planning, and clinical trial design. Further validation studies are necessary.

\section{REFERENCES}

Corti A, Franzini M, Paolicchi A, Pompella A (2010) Gammaglutamyltransferase of cancer cells at the crossroads of tumor progression, drug resistance and drug targeting. Anticancer Res 30: 1169-1181.

de Martino M, Hoetzenecker K, Ankersmit HJ, Roth GA, Haitel A, Waldert M, Klatte T (2012a) Serum 20S proteasome is elevated in patients with renal cell carcinoma and associated with poor prognosis. Br J Cancer 106: 904-908.

de Martino M, Klatte T, Haitel A, Marberger M (2012b) Serum cell-free DNA in renal cell carcinoma: a diagnostic and prognostic marker. Cancer 118: 82-90.

de Martino M, Klatte T, Seemann C, Waldert M, Haitel A, Schatzl G, Remzi M, Weibl P (2013) Validation of serum C-reactive protein (CRP) as an independent prognostic factor for disease-free survival in patients with localised renal cell carcinoma (RCC). BJU Int 111: E348-E353.

Ficarra V, Martignoni G, Lohse C, Novara G, Pea M, Cavalleri S, Artibani W (2006) External validation of the Mayo Clinic Stage, Size, Grade and Necrosis (SSIGN) score to predict cancer specific survival using a European series of conventional renal cell carcinoma. J Urol 175: 1235-1239.

Fischer P, Scherberich JE (1996) Hybridomas reveal shared immunodominant epitopes of gamma-glutamyltransferase isoforms from human kidney and renal cell carcinoma. Tumour Biol 17: 369-377.

Fischer P, Störkel S, Haase W, Scherberich JE (1991) Differential diagnosis of histogenetically distinct human epithelial renal tumours with a monoclonal antibody against gamma-glutamyltransferase. Cancer Immunol Immunother 33: 382-388.

Frank I, Blute ML, Cheville JC, Lohse CM, Weaver AL, Zincke H (2002) An outcome prediction model for patients with clear cell renal cell carcinoma treated with radical nephrectomy based on tumor stage, size, grade and necrosis: the SSIGN score. J Urol 168: 2395-2400.

Grimm C, Hofstetter G, Aust S, Mutz-Dehbalaie I, Bruch M, Heinze G, Rahhal-Schupp J, Reinthaller A, Concin N, Polterauer S (2013) Association of gamma-glutamyltransferase with severity of disease at diagnosis and prognosis of ovarian cancer. Br J Cancer 109: 610-614.

Hanigan MH, Frierson HF (1996) Immunohistochemical detection of gammaglutamyl transpeptidase in normal human tissue. J Histochem Cytochem 44: 1101-1108.

Hanigan MH, Ricketts WA (1993) Extracellular glutathione is a source of cysteine for cells that express gamma-glutamyl transpeptidase. Biochemistry 32: 6302-6306.

Heng DYC, Xie W, Regan MM, Harshman LC, Bjarnason GA, Vaishampayan UN, Mackenzie M, Wood L, Donskov F, Tan M-H, Rha S-Y, Agarwal N, Kollmannsberger C, Rini BI, Choueiri TK (2013) External validation and comparison with other models of the International Metastatic Renal-Cell Carcinoma Database Consortium prognostic model: a population-based study. Lancet Oncol 14: 141-148.

Jemal A, Bray F, Center MM, Ferlay J, Ward E, Forman D (2011) Global cancer statistics. CA Cancer J Clin 61: 69-90.

Kaufmann O, Dietel M, Scherberich JE, Gaedicke G, Fischer P (1997) Immunohistochemical differentiation of metastases of renal carcinomas versus other carcinomas with anti-gamma GT monoclonal antibody 138H11. Histopathology 31: 31-37.

Kroeger N, Xie W, Lee J-L, Bjarnason GA, Knox JJ, Mackenzie MJ, Wood L, Srinivas S, Vaishamayan UN, Rha S-Y, Pal SK, Yuasa T, Donskov F, Agarwal N, Kollmannsberger CK, Tan M-H, North SA, Rini BI, Choueiri TK, Heng DYC (2013) Metastatic non-clear cell renal cell carcinoma treated with targeted therapy agents: characterization of survival outcome and application of the International mRCC Database Consortium criteria. Cancer 119: 2999-3006.
Lee DS, Evans JC, Robins SJ, Wilson PW, Albano I, Fox CS, Wang TJ, Benjamin EJ, D'Agostino RB, Vasan RS (2007) Gamma glutamyl transferase and metabolic syndrome, cardiovascular disease, and mortality risk: the Framingham Heart Study. Arterioscler Thromb Vasc Biol 27: 127-133.

Ljungberg B, Cowan NC, Hanbury DC, Hora M, Kuczyk MA, Merseburger AS, Patard J-J, Mulders PFA, Sinescu IC (2010) EAU guidelines on renal cell carcinoma: the 2010 update. Eur Urol 58: 398-406.

Lusini L, Tripodi SA, Rossi R, Giannerini F, Giustarini D, del Vecchio MT, Barbanti G, Cintorino M, Tosi P, Di Simplicio P (2001) Altered glutathione anti-oxidant metabolism during tumor progression in human renal-cell carcinoma. Int J Cancer 91: 55-59.

Mazumdar M, Glassman JR (2000) Categorizing a prognostic variable: review of methods, code for easy implementation and applications to decisionmaking about cancer treatments. Stat Med 19: 113-132.

McShane LM, Altman DG, Sauerbrei W, Taube SE, Gion M, Clark GM (2005) REporting recommendations for tumour MARKer prognostic studies (REMARK). Br J Cancer 93: 387-391.

Pastore A, Federici G, Bertini E, Piemonte F (2003) Analysis of glutathione: implication in redox and detoxification. Clin Chim Acta 333: 19-39.

Pichler M, Hutterer GC, Stojakovic T, Mannweiler S, Pummer K, Zigeuner R (2013) High plasma fibrinogen level represents an independent negative prognostic factor regarding cancer-specific, metastasis-free, as well as overall survival in a European cohort of non-metastatic renal cell carcinoma patients. Br J Cancer 109: 1123-1129.

Polterauer S, Hofstetter G, Grimm C, Rahhal J, Mailath-Pokorny M, Kohl M, Concin N, Tempfer C, Marth C, Reinthaller A (2011) Relevance of gamma-glutamyltransferase-a marker for apoptotic balance-in predicting tumor stage and prognosis in cervical cancer. Gynecol Oncol 122: $590-594$.

Procopio G, Verzoni E, Iacovelli R, Biasoni D, Testa I, Porcu L, De Braud F (2012) Prognostic factors for survival in patients with metastatic renal cell carcinoma treated with targeted therapies. Br J Cancer 107: 1227-1232.

Ramankulov A, Lein M, Kristiansen G, Meyer H-A, Loening SA, Jung K (2007) Elevated plasma osteopontin as marker for distant metastases and poor survival in patients with renal cell carcinoma. J Cancer Res Clin Oncol 133: 643-652.

Russo A, DeGraff W, Friedman N, Mitchell JB (1986) Selective modulation of glutathione levels in human normal versus tumor cells and subsequent differential response to chemotherapy drugs. Cancer Res 46 : 2845-2848.

Sandock DS, Seftel AD, Resnick MI (1997) The role of gamma-glutamyl transpeptidase in the preoperative metastatic evaluation of renal cell carcinoma. J Urol 157: 798-799.

Schiele F, Guilmin AM, Detienne H, Siest G (1977) Gammaglutamyltransferase activity in plasma: statistical distributions, individual variations, and reference intervals. Clin Chem 23: 1023-1028.

Seebacher V, Polterauer S, Grimm C, Rahhal J, Hofstetter G, Bauer E-M, Husslein H, Leipold H, Marth C, Reinthaller A, Concin N (2012) Prognostic significance of gamma-glutamyltransferase in patients with endometrial cancer: a multi-centre trial. Br J Cancer 106: 1551-1555.

Simic T, Dragicevic D, Savic-Radojevic A, Cimbaljevic S, Tulic C, Mimic-Oka J (2007) Serum gamma glutamyl-transferase is a sensitive but unspecific marker of metastatic renal cell carcinoma. Int J Urol 14: 289-293.

Strasak AM, Goebel G, Concin H, Pfeiffer RM, Brant LJ, Nagel G, Oberaigner W, Concin N, Diem G, Ruttmann E, Gruber-Moesenbacher U, Offner F, Pompella A, Pfeiffer KP, Ulmer H (2010) Prospective study of the association of serum gamma-glutamyltransferase with cervical intraepithelial neoplasia III and invasive cervical cancer. Cancer Res 70: 3586-3593.

Whitfield JB (2001) Gamma glutamyl transferase. Crit Rev Clin Lab Sci 38: 263-355.

Zisman A, Pantuck AJ, Wieder J, Chao DH, Dorey F, Said JW, deKernion JB, Figlin RA, Belldegrun AS (2002) Risk group assessment and clinical outcome algorithm to predict the natural history of patients with surgically resected renal cell carcinoma. J Clin Oncol 20: 4559-4566.

This work is published under the standard license to publish agreement. After 12 months the work will become freely available and the license terms will switch to a Creative Commons AttributionNonCommercial-Share Alike 3.0 Unported License. 